The Version of Record of this manuscript has been published and is available in

Clinical Gerontologist 2016 http://www.tandfonline.com/10.1080/07317115.2015.1120255

To cite this article: Bornet, M. A., Rochat, E., Dürst A. V., Fustinoni, S., Büla, C., von Gunten, A., \& Monod, S. (2016). Instruments to Assess Depressive Symptoms and Spiritual Distress Investigate Different Dimensions. Clinical Gerontologist, 39, 104-116. doi:10.1080/07317115.2015.1120255 


\section{Instruments to Assess Depressive Symptoms and Spiritual Distress}

\section{Investigate Different Dimensions}

Marc-Antoine Bornet, Etienne Rochat, Anne-Véronique Dürst, Sarah Fustinoni, Christophe Büla, Armin von Gunten and Stéfanie Monod Lausanne University Hospital Center, Switzerland

\section{Author Note}

Marc-Antoine Bornet, Service of Geriatric Medicine \& Geriatric Rehabilitation, Lausanne University Hospital Center; Etienne Rochat, Chaplaincy Service, Lausanne University Hospital Center; Anne-Véronique Dürst, Service of Geriatric Medicine \& Geriatric Rehabilitation, Lausanne University Hospital Center; Sarah Fustinoni, Institute of Social and Preventive Medicine, Lausanne University Hospital Center; Christophe Büla, Service of Geriatric Medicine \& Geriatric Rehabilitation, Lausanne University Hospital Center; Armin von Gunten, Service of Old Age Psychiatry, Lausanne University Hospital Center; Stéfanie Monod, Department of Medicine, Lausanne University Hospital Center.

Address correspondence to Marc-Antoine Bornet, Service of Geriatric Medicine \& Geriatric Rehabilitation, Lausanne University Hospital Center (CHUV), 1011 Lausanne, Switzerland. E-mail: marc-antoine.bornet@chuv.ch 


\begin{abstract}
Although affective and spiritual states may share some common clinical features, the precise nature of the relationship between depression and spirituality is still unclear. We tested the hypothesis that two instruments that measure depressive symptoms and spiritual distress describe similar dimensions.

Patients admitted to geriatric rehabilitation $(\mathrm{N}=185$; mean age $81.3 \pm 6.9$ years $)$ had depressive symptoms assessed with the 15-item Geriatric Depression Scale (GDS-15) and spiritual distress evaluated with the Spiritual Distress Assessment Tool (SDAT).

A principal components analysis pooling GDS-15 and SDAT resulted in a 6-factor solution, with only one factor shared by both dimensions.

Depressive symptoms and spiritual distress measured by the two instruments appeared only moderately correlated and corresponded to distinct dimensions.
\end{abstract}

Keywords: depression; Geriatric Depression Scale; spirituality; spiritual distress, geriatric rehabilitation 


\section{Instruments to Assess Depressive Symptoms and Spiritual Distress}

\section{Investigate Different Dimensions}

Depression is prevalent in elderly people (Beekman, Copeland, \& Prince, 1999; Helvik, Skancke, \& Selbaek, 2010) and associated with poor health outcomes, such as increased functional decline and higher mortality (Blazer, 2003). As depression in elderly people is often underdiagnosed and undertreated (Mulsant \& Ganguli, 1999), guidelines usually recommend screening elderly people for depression (Nakajima \& Wenger, 2007).

Among instruments proposed to screen for depression, the Geriatric Depression Scale (GDS) (Yesavage et al., 1983) is one of the most widely used in various geriatric populations and settings (Dennis, Kadri, \& Coffey, 2012; Kim, DeCoster, Huang, \& Bryant, 2013; Watson \& Pignone, 2003). Yesavage et al. constructed the GDS by selecting 100 questions in a yes/no format that potentially indicated depression in elderly people. They then determined the 30 most discriminating items in a population $(\mathrm{N}=47$, aged 55 years and over $)$ of healthy community-dwelling and hospitalized elderly people (Yesavage et al., 1983). The initial factorial analysis of the GDS identified five dimensions: sad mood and pessimistic outlook, lack of energy, positive mood, agitation, and social withdrawal (Sheikh et al., 1991).

The 15-item version of the GDS (GDS-15) was developed using the fifteen best discriminating questions from the initial 30-item version of the GDS (Sheikh \& Yesavage, 1986). This shorter version also showed satisfactory performance (Wancata, Alexandrowicz, Marquart, Weiss, \& Friedrich, 2006). For example, in a study among hospitalized elderly patients $(\mathrm{N}=150)$, a score of six or more on the GDS-15 showed adequate sensitivity and specificity (83\% and 80\%, respectively) to detect depression (Blank, Gruman, \& Robison, 2004). 
Given the wide initial construct of the GDS, the GDS-15 may capture symptoms associated with both depressive as well as spiritual problems. Indeed, some symptoms of distress - such as discouragement, wish for death, poor self-image - may indicate both depressive and spiritual distress states (Brown, Whitney, \& Duffy, 2006; Villagomeza, 2005). Therefore, some items on the GDS-15 such as "Do you often feel helpless?" or "Do you feel that your life is empty?" may reveal symptoms of depression or some spiritual/existential distress.

Exploring the potential relationship between GDS-15 and spirituality could therefore be important. However, to address this issue, spiritual distress must be clearly defined.

Spirituality in health care has received increasing attention during the past few decades. Initially, most studies focused on religiosity - a well-defined concept - but current research is increasingly based on a wider concept of spirituality. An international consensus conference suggested the following definition of spirituality in health care: "Spirituality is a dynamic and intrinsic aspect of humanity through which persons seek ultimate meaning, purpose, and transcendence, and experience relationship to self, family, others, community, society, nature, and the significant or sacred. Spirituality is expressed through beliefs, values, traditions, and practices.” (Puchalski, Vitillo, Hull, \& Reller, 2014).

Many studies have focused on the positive influence of spirituality on health outcomes. Researchers now generally agree that spirituality plays a role in psychological well-being and positive coping with illness (Huguelet \& Koenig, 2009). Several studies also demonstrated an inverse relationship between spiritual well-being and depression (Bekelman et al., 2007; McClain, Rosenfeld, \& Breitbart, 2003; Nelson, Rosenfeld, Breitbart, \& Galietta, 2002; Rosmarin, Malloy, \& Forester, 2014). For instance, Daaleman et al. found a significant inverse correlation between spiritual well-being and depressive symptoms with the GDS-15 in 
community-dwelling elderly persons (Daaleman, Frey, Wallace, \& Studenski, 2002).

However, some criticism has been addressed to this work, as some have argued that spirituality constructs are too vague or too similar to psychological constructs, thereby explaining the relationship between these two dimensions. Indeed, many spirituality constructs/questionnaires, especially those measuring spiritual well-being, contain domains/items directly referring to emotional well-being (Moreira-Almeida \& Koenig, 2006; Visser, Garssen, \& Vingerhoets, 2010). For example, "I am satisfied with my life" in the JAREL spiritual well-being scale (Hungelmann, Kenkel-Rossi, Klassen, \& Stollenwerk, 1989) is similar to the GDS-15 question "Are you basically satisfied with your life?" Similarly, "There is a great void in my life at this time" included in the Spirituality Index of Well-Being (Daaleman \& Frey, 2004) is similar to the GDS-15 item "Do you feel that your life is empty?"

To further explore this potential overlap between spirituality and depression constructs, we decided to adopt a different approach and to use an instrument specifically designed to assess spiritual distress (the Spiritual Distress Assessment Tool, SDAT) (Monod, Rochat, Büla, Jobin, et al., 2010; Monod, Martin, Spencer, Rochat, \& Büla, 2012) instead of using an instrument with a spiritual well-being construct (Figure 1). This original approach uses definitions of psychological and spiritual states oriented toward the same direction. 


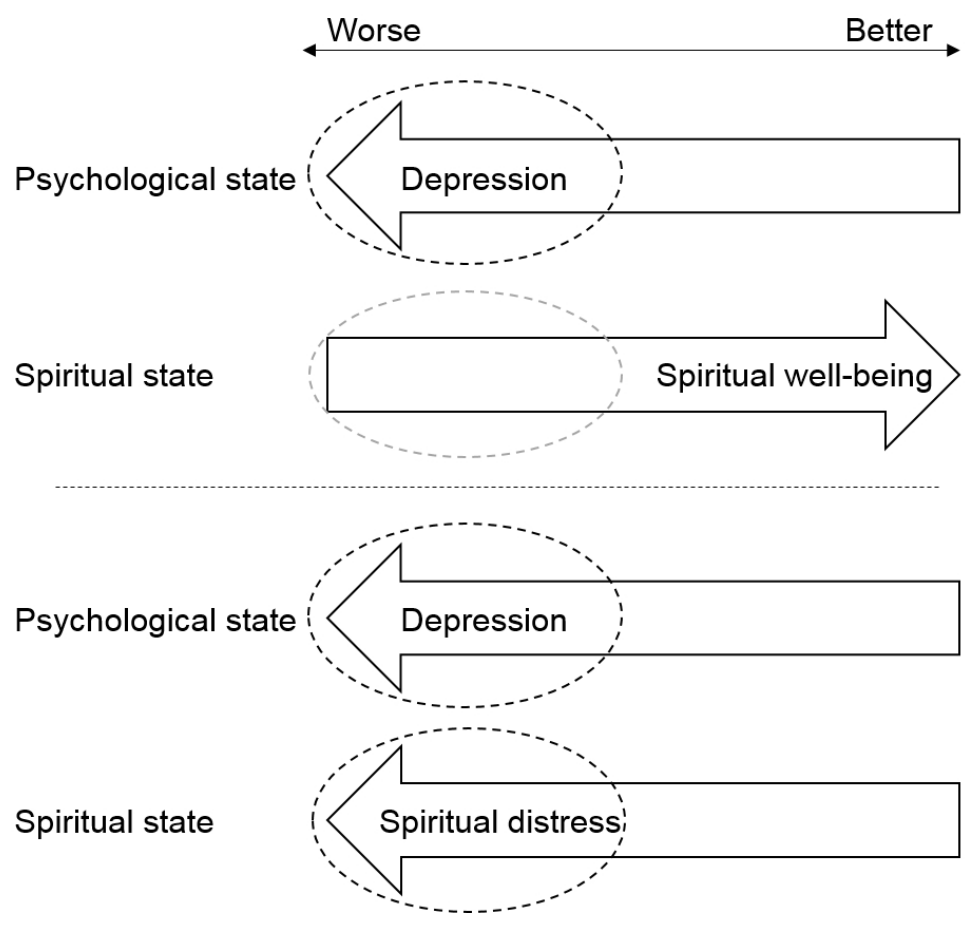

Figure 1. Conceptual model underlying this research.

Therefore, the objective of this study was to determine overlaps and differences between two instruments that measure depressive symptoms (GDS-15) and spiritual distress (SDAT) in a population of elderly patients admitted to geriatric rehabilitation. In the present study, we hypothesized that these instruments describe identical dimensions. To test this hypothesis, three specific objectives were defined: 1) to determine the correlations between GDS-15 and SDAT scores; 2) to perform a principal components analysis pooling GDS-15 and SDAT items; and 3) to investigate the relationships between each item of the GDS-15 and each unmet spiritual need. 


\section{Method}

\section{Setting and population}

This study used data from patients included in a previous study aimed to measure spiritual distress in elderly patients aged 65 years or older who were consecutively admitted over a 6-month period to a post-acute rehabilitation unit of the Service of Geriatric Medicine and Rehabilitation at Lausanne University Hospital Center, Switzerland (Monod et al., 2012).

Patients were included if they were able to speak French, had no significant cognitive impairment (defined as a score less than 20 on the Mini Mental State Exam, MMSE) (Folstein, Folstein, \& McHugh, 1975), and were not considered too ill to participate (medically unstable or with uncontrolled symptoms such as severe pain, dyspnea, etc.).

Overall, 305 of the $410(74.4 \%)$ patients admitted to the unit met the inclusion criteria. Of these, 97 refused to participate, five left the unit before completing the assessment interview, and 18 had incomplete GDS-15 scales, leaving a final sample of 185 subjects. An analysis comparing participants $(\mathrm{N}=185)$ with patients who refused to participate or had missing data $(\mathrm{N}=120)$ showed no significant differences (for characteristics mentioned in Table 1, see below), except for gender distribution (71.9\% vs. $60.8 \%$ women in accepters and refusers, respectively, $p=.044)$.

The Canton of Vaud Human Research Ethics Committee approved the study, and all participants signed informed consent.

\section{Data collection}

Information on age, gender, living arrangements, functional (basic activities of daily living, ADL) (Katz, Downs, Cash, \& Grotz, 1970) and cognitive (Mini Mental State Exam, MMSE) (Folstein et al., 1975) status were collected at admission.

15-item Geriatric Depression Scale (GDS-15). Depressive symptoms were assessed 
using the GDS-15 on the day of admission by the physician in charge of the patient. The GDS-15 contains 15 questions with a yes-no answer format. One point is given for each answer indicating depressed mood. We used the 15-item French version (Cialdella et al., 1992), with a cut-off score of 6 or more to detect significant depressive symptoms (Blank et al., 2004).

Spiritual Distress Assessment Tool (SDAT). Spiritual distress was assessed using the SDAT, a validated tool to assess spiritual distress in elderly hospitalized patients (Monod, Rochat, Büla, Jobin, et al., 2010; Monod et al., 2012). In the SDAT construct, spirituality is conceptualized as “the particular coherence expressed when describing one's meaning of life, referring to one's transcendence, and explaining one's values" (Monod, Rochat, Büla, \& Spencer, 2010). This concept includes four dimensions (Meaning; Transcendence; Values; and Psychosocial identity), and five related spiritual needs (need for life balance; need for connection; need for values' acknowledgement, need to maintain control; and need to maintain identity). Spiritual distress arises from unmet spiritual needs. The greater the degree to which a spiritual need remains unmet, the greater the disturbance in spiritual state and the greater the level of spiritual distress experienced by the patient (Monod et al., 2012). Interviews were conducted by a trained chaplain within three days after admission. The chaplain investigated in a semi-structured format the various spiritual needs which were scored on a 4-point Likert scale (0 to 3), resulting in a total SDAT score that ranged from 0 (no distress) to 15 (severe distress). Spiritual distress is defined as a score $\geq 5$ because this cut-off corresponds to a range of situations with unmet needs considered as significant either in terms of severity (e.g., one severe unmet spiritual need [score $=3$ ] combined with some other slightly unmet spiritual need) or in terms of extent (e.g., unmet spiritual need in all dimensions) (Monod, Rochat, Büla, Jobin, et al., 2010; Monod et al., 2012). 


\section{Statistical analysis}

Descriptive analyses of the variables were performed. Correlation between GDS-15 and SDAT scores was calculated using Spearman's rank correlation coefficient. Principal components analysis pooling GDS-15 and SDAT items, with varimax rotation, was performed. Only factors with an eigenvalue $>1$ were retained in the model (Kaiser-Guttman rule). Relationships between each GDS-15 item and each spiritual need were tested using Pearson's Chi square test (or Fischer's exact test if expected frequencies were less than 5). Statistical significance was set at $p \leq .050$. All analyses were performed using Stata version 12.0 software. 


\section{Results}

\section{Population characteristics}

Participants $(\mathrm{N}=185)$ had a mean age of $81.3 \pm 6.9$ years; $71.9 \%$ were women. Their characteristics are summarized in Table 1.

\section{Table 1}

Clinical characteristics of the sample.

\begin{tabular}{lc}
\hline Characteristics & $\begin{array}{c}\text { Study population } \\
(\mathrm{N}=185)\end{array}$ \\
\hline Age (years), mean \pm SD & $81.3 \pm 6.9$ \\
[min; max] & {$[65 ; 98]$} \\
Women (\%) & 71.9 \\
Living alone (\%) & 56.9 \\
MMSE & $26.8 \pm 2.6$ \\
Cognitive impairment ${ }^{\text {a }}(\%)$ & {$[20 ; 30]$} \\
ADL index at admission & 15.1 \\
Home care before hospitalisation $(\%)$ & $3.3 \pm 1.5$ \\
Hospital length of stay (days) & {$[1 ; 6]$} \\
Back home at discharge $(\%)$ & 43.4 \\
Home care at discharge $(\%)$ & $23.5 \pm 15.2$ \\
Readmission within 30 days $(\%)$ & {$[2 ; 98]$} \\
\hline
\end{tabular}

Note. $\mathrm{SD}=$ standard deviation; MMSE $=$ Mini-Mental State Examination; $\mathrm{ADL}=$ Activity of Daily Living.

${ }^{\mathrm{a} C o g n i t i v e ~ i m p a i r m e n t ~ d e f i n e d ~ a s ~ a ~ M M S E ~ s c o r e ~}<24$.

Overall, the mean GDS-15 score was $2.6 \pm 2.6$ (range $0-13$; median 2), and $15.7 \%$ of the patients had significant depressive symptoms (GDS-15 score $\geq 6$ ).

The mean SDAT score was $5.6 \pm 2.4$ (range 1-11; median 6), and $64.9 \%$ of the patients had significant spiritual distress (SDAT score $\geq 5$ ). In this study, 23.8\% reported one severe unmet spiritual need in at least one dimension, and $25.9 \%$ reported some distress on all five 
spiritual needs. Nearly all patients (97.8\%) reported some distress on the Need for life balance. Moreover, the Need for life balance accounted for the most frequent occurrence of severely unmet spiritual needs.

Overall, $15.1 \%$ of participants had simultaneous spiritual distress and significant depressive symptoms.

\section{Relationship between GDS-15 and SDAT scores}

First, to compare the two scores, the variables were treated as numerical scales. Figure 2 shows the distribution of the two scores.

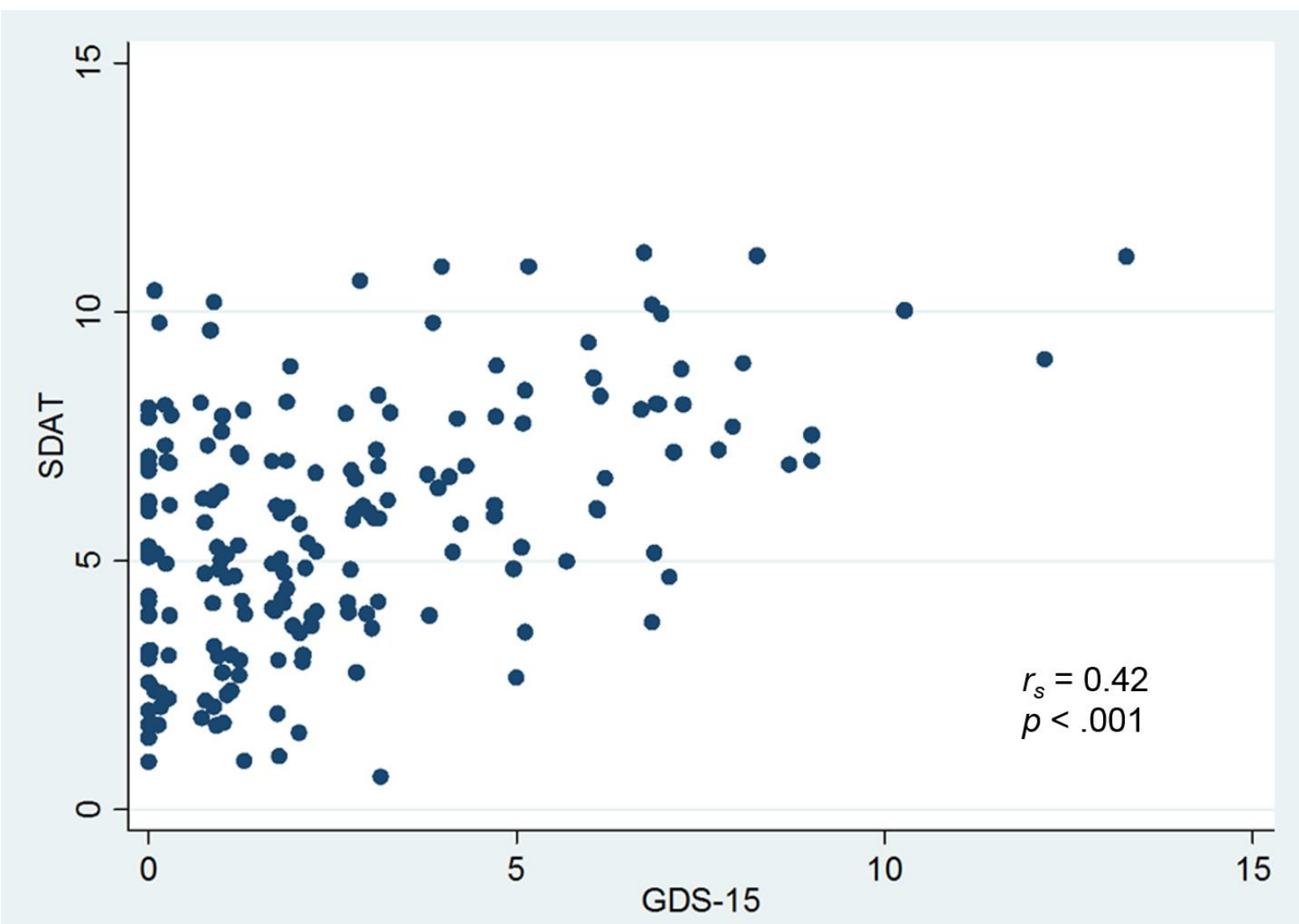

Figure 2. Relationship between 15-item Geriatric Depression Scale (GDS-15) and Spiritual

Distress Assessment Tool (SDAT) scores. Spherical random noise was introduced to disperse overlapping points. Spearman's rank correlation coefficient: $r_{s}=0.42 ; p<.001$. 
A moderate positive correlation between the GDS-15 and the SDAT was found $\left(r_{s}=\right.$ 0.42; $p<.001)$. Subjects with low GDS-15 score presented a wide range of SDAT scores, whereas those with high GDS-15 score tended to systematically score high on the SDAT. Indeed, $96.4 \%(27 / 28)$ of patients with significant depressive symptoms (GDS-15 $\geq 6$ ) also suffered from spiritual distress. Conversely, patients with high SDAT scores had a wide range of scores on the GDS-15.

Subjects with significant spiritual distress $(\mathrm{SDAT} \geq 5)$ had more depressive symptoms than those without spiritual distress (mean GDS-15 score $3.3 \pm 2.9$ [median 3.0; interquartile range 4.0] vs. $1.4 \pm 1.4[1.0 ; 2.0], p<.001)$.

\section{Principal components analysis of SDAT and GDS-15 items}

A principal components analysis pooling GDS-15 and SDAT components resulted in a 6-factor solution accounting for 55\% of the variance (Kaiser-Meyer-Olkin 0.77, all variables $>0.5)$ (Table 2).

Correlations between items and rotated factors were used to identify which items contributed to the factors. Only items with factor loadings greater than or equal to 0.40 were selected. However, there were three items for which loadings were higher than or equal to 0.40 on more than one factor (GDS-15 items 2, 7, and 8). In these specific cases, these items were associated with the factor on which they loaded most (Factor 5, Factor 4, and Factor 5, respectively). 
Table 2

Principal components analysis pooling 15-item Geriatric Depression Scale (GDS-15) and

Spiritual Distress Assessment Tool (SDAT) items gave a 6-factor solution, accounting for 55\%

of the variance: Factor loadings after varimax rotation.

\begin{tabular}{|c|c|c|c|c|c|c|}
\hline Items & Factor 1 & Factor 2 & Factor 3 & Factor 4 & Factor 5 & Factor 6 \\
\hline $\begin{array}{l}\text { gds } 1: \text { Are you basically satisfied with your } \\
\text { life? No }\end{array}$ & .58 & -.08 & .30 & .22 & .17 & .16 \\
\hline $\begin{array}{l}\text { gds } 2: \text { Have you dropped many of your } \\
\text { activities and interests? Yes }\end{array}$ & .23 & .02 & .02 & -.03 & .56 & .44 \\
\hline gds 3 Do you feel that your life is empty? Yes & .07 & .22 & .53 & .24 & .13 & .17 \\
\hline gds 4 : Do you often get bored? Yes & -.23 & .19 & .71 & .11 & .06 & .10 \\
\hline $\begin{array}{l}\text { gds } 5 \text { : Are you in good spirits most of the } \\
\text { time? No }\end{array}$ & .14 & .13 & .11 & .81 & -.04 & -.01 \\
\hline $\begin{array}{l}\text { gds } 6: \text { Are you afraid that something bad is } \\
\text { going to happen to you? Yes }\end{array}$ & -.03 & -.07 & .01 & .13 & .75 & -.05 \\
\hline $\begin{array}{l}\text { gds } 7 \text { : Do you feel happy most of the time? } \\
\text { No }\end{array}$ & .10 & -.03 & .42 & .67 & .15 & .02 \\
\hline gds 8 : Do you often feel helpless? Yes & .21 & .09 & .40 & -.05 & .59 & -.02 \\
\hline $\begin{array}{l}\text { gds } 9 \text { : Do you prefer to stay at home, rather } \\
\text { than going out and doing new things? Yes }\end{array}$ & .64 & .06 & -.11 & .09 & .08 & -.11 \\
\hline $\begin{array}{l}\text { gds } 10 \text { : Do you feel you have more problems } \\
\text { with memory than most? Yes }\end{array}$ & .11 & -.01 & .08 & .17 & -.14 & .73 \\
\hline $\begin{array}{l}\text { gds } 11 \text { : Do you think it is wonderful to be } \\
\text { alive now? No }\end{array}$ & .22 & .03 & .67 & .16 & .15 & .01 \\
\hline $\begin{array}{l}\text { gds } 12 \text { : Do you feel pretty worthless the way } \\
\text { you are now? Yes }\end{array}$ & .39 & -.01 & .48 & -.23 & .29 & .31 \\
\hline gds 13 : Do you feel full of energy? No & .61 & .12 & .26 & -.11 & -.11 & .16 \\
\hline $\begin{array}{l}\text { gds } 14 \text { : Do you feel that your situation is } \\
\text { hopeless? Yes }\end{array}$ & .27 & -.06 & .64 & .10 & -.09 & .07 \\
\hline $\begin{array}{l}\text { gds } 15 \text { : Do you think that most people are } \\
\text { better off than you are? Yes }\end{array}$ & .02 & .04 & .11 & -.08 & .12 & .66 \\
\hline SDAT Need for life balance & -.13 & .42 & .15 & .32 & .29 & .34 \\
\hline SDAT Need for connection & .39 & .14 & .07 & .37 & .07 & .29 \\
\hline SDAT Need for values' acknowledgement & .13 & .77 & .17 & .10 & .04 & .04 \\
\hline SDAT Need to maintain control & .14 & .82 & -.02 & .00 & -.11 & -.03 \\
\hline SDAT Need to maintain identity & .49 & .23 & .13 & .20 & .13 & .10 \\
\hline Eigenvalue & 2.02 & 1.67 & 2.48 & 1.67 & 1.58 & 1.58 \\
\hline
\end{tabular}

Note. GDS-15 items are designated in numerical order and SDAT items by their names. Factor loadings $\geq .40$ are in boldface 
Factor 1 shared items from both SDAT and GDS-15 (10\% of explained variance after rotation; gds 9, gds 13, gds 1, and SDAT Need to maintain identity). The spiritual need "SDAT Need for connection" was not significantly associated with a factor (factor loading higher or equal to 0.40); nevertheless, the strongest correlation was observed on Factor 1 (factor loading 0.39).

Factor 2 included only SDAT items (8\%; SDAT Need to maintain control, SDAT Need for values' acknowledgement, and SDAT Need for life balance), whereas all the other factors included only GDS-15 items: Factor 3 (12\%; gds 4, gds 11, gds 14, gds 3, and gds 12), Factor 4 (8\%; gds 5 and gds 7), Factor 5 (8\%; gds 6, gds 8, and gds 2) and Factor 6 (8\%; gds 10 and gds 15).

\section{Relationships between GDS-15 and SDAT items}

Table 3 shows the relationships between each item of the GDS-15 and each unmet spiritual need.

GDS-15 items with a statistically significant difference between unmet and satisfied spiritual needs were not specifically related to a spiritual need. 
Table 3

Percentages of answers suggesting depressive symptoms for each item of the 15-item

Geriatric Depression Scale (GDS-15) according to the presence of various unmet spiritual needs. GDS-15 items with a statistically significant difference $(p \leq .050)$ between unmet and satisfied spiritual needs are indicated in boldface.

\begin{tabular}{|c|c|c|c|c|c|c|c|}
\hline \multirow[b]{2}{*}{$\begin{array}{l}\text { GDS-15 } \\
\text { item }\end{array}$} & \multicolumn{5}{|c|}{ Moderate unmet (score $\geq 2$ ) need for/to ... } & \multirow[b]{2}{*}{$\begin{array}{c}\text { Spiritual } \\
\text { distress } \\
(\mathrm{SDAT} \geq 5) \\
(\mathrm{N}=120)\end{array}$} & \multirow[b]{2}{*}{$\begin{array}{c}\text { Study } \\
\text { sample } \\
(\mathrm{N}=185)\end{array}$} \\
\hline & $\begin{array}{c}\text { life } \\
\text { balance } \\
(\mathrm{N}=134)\end{array}$ & $\begin{array}{c}\text { Connection } \\
(\mathrm{N}=45)\end{array}$ & $\begin{array}{c}\text { values' } \\
\text { acknowledge } \\
\text { ment } \\
(\mathrm{N}=33)\end{array}$ & $\begin{array}{c}\text { maintain } \\
\text { control } \\
(\mathrm{N}=40)\end{array}$ & $\begin{array}{l}\text { maintain } \\
\text { identity } \\
(\mathrm{N}=83)\end{array}$ & & \\
\hline gds 1 & 14.9 & 26.7 & 21.2 & 12.5 & 25.3 & 19.2 & 13.5 \\
\hline gds 2 & 38.1 & 44.4 & 36.4 & 35.0 & 39.8 & 37.5 & 33.5 \\
\hline gds 3 & 21.6 & 28.9 & 36.4 & 22.5 & 26.5 & 22.5 & 16.8 \\
\hline gds 4 & 12.7 & 15.6 & 21.2 & 10.0 & 14.5 & 14.2 & 9.7 \\
\hline gds 5 & 8.2 & 15.6 & 18.2 & 5.0 & 10.8 & 9.2 & 6.5 \\
\hline gds 6 & 21.6 & 24.4 & 18.2 & 12.5 & 22.9 & 21.7 & 18.4 \\
\hline gds 7 & 7.5 & 17.8 & 18.2 & 2.5 & 10.8 & 10.0 & 6.5 \\
\hline gds 8 & 37.3 & 44.4 & 36.4 & 32.5 & 42.2 & 38.3 & 30.3 \\
\hline gds 9 & 32.8 & 44.4 & 36.4 & 40.0 & 44.6 & 38.3 & 34.6 \\
\hline gds 10 & 17.9 & 22.2 & 21.2 & 17.5 & 19.3 & 18.3 & 14.6 \\
\hline gds 11 & 11.2 & 17.8 & 15.2 & 10.0 & 15.7 & 13.3 & 9.2 \\
\hline gds 12 & 20.9 & 31.1 & 24.2 & 15.0 & 26.5 & 22.5 & 17.3 \\
\hline gds 13 & 32.1 & 42.2 & 42.4 & 35.0 & 42.2 & 37.5 & 30.3 \\
\hline gds 14 & 11.2 & 20.0 & 18.2 & 5.0 & 13.3 & 11.7 & 9.2 \\
\hline gds 15 & 15.7 & 17.8 & 15.2 & 20.0 & 18.1 & 14.2 & 13.0 \\
\hline $\begin{array}{l}\text { Mean total } \\
\text { GDS-15 } \\
\text { score }^{\mathrm{a}}\end{array}$ & $3.04 \pm 2.81$ & $4.13 \pm 3.45$ & $3.79 \pm 3.08$ & $\begin{array}{c}2.75 \pm \\
2.70\end{array}$ & $\begin{array}{c}3.72 \pm \\
3.08\end{array}$ & $3.28 \pm 2.91$ & $2.63 \pm 2.64$ \\
\hline
\end{tabular}




\section{Discussion}

In this study, in which we used an original approach of using definitions of psychological and spiritual states oriented toward the same direction, depressive symptoms and spiritual distress corresponded to distinct dimensions.

Within this population of older patients admitted to geriatric rehabilitation, depressive symptoms and spiritual distress were only moderately associated. The results provide unique information in showing that the presence of significant depressive symptoms (GDS-15 score of 6 or more) was almost always associated with the presence of spiritual distress, whereas patients with low GDS-15 scores had a large range of SDAT scores. These results enhance our understanding of the overlapping relationship between depression and spiritual distress and show that patients with significant depressive symptoms might be especially vulnerable to concomitant spiritual distress.

The principal components analysis revealed slightly overlapping but clearly distinct symptoms associated with depressive symptoms and spiritual distress. Only one factor included both components of the GDS-15 and the SDAT (Need to maintain identity): however, correlations between Factor 1 and SDAT items (Need to maintain identity, Need for connection) remain weak, not exceeding a factor loading of 0.50 .

Similarly, analysis of the relationships between each GDS-15 item and each unmet spiritual need showed a large diffusion of correlations, without a clear association. Especially, no spiritual need was clearly better correlated to the GDS-15.

Overall, the results refute the initial hypothesis that GDS-15 items cover spiritual dimensions. Indeed, we found some relationship but never a significant overlap. No factor had strong correlations for both the GDS-15 and the SDAT, and no spiritual need of the SDAT was better correlated with the GDS-15. Finally, our results highlight the differences between the 
GDS-15 and the SDAT instruments.

\section{Clinical implications}

The high prevalence and sometimes coexistence of depression and spiritual distress in elderly patients is expected because they are struggling with issues related to death or institutionalization after an acute care stay. However, distinguishing between patients suffering from depression and those suffering from spiritual distress is important, as interventions to address these two problems may differ. Patients suffering from depression should benefit from treatments including antidepressant use and psychotherapeutic interventions. Although the best approach to manage these patients remains essentially unknown, patients suffering from spiritual distress might benefit from other specific interventions (e.g., spiritual care with a chaplain in coordination with interdisciplinary care team) (Balboni, Puchalski, \& Peteet, 2014; Puchalski et al., 2014). Distinguishing spiritual distress from depression will prevent inappropriate medicalization or pathologization and eventually inappropriate treatment of older patients with antidepressants. For both depression and spiritual distress, an interdisciplinary biopsychosocial-spiritual approach, viewing patients as whole persons, may be desirable and necessary to improve the care of elderly patients (Sulmasy, 2002).

\section{Strengths and weaknesses of the study}

Most studies that investigated spiritual distress used instruments designed for the assessment of spiritual well-being rather than spiritual distress. A clear strength of the present study is the use of a tool specifically validated to capture spiritual distress, a dimension that could significantly differ from low spiritual well-being. The concept of spiritual distress underlying the SDAT was developed according to a rigorously structured process with further specification of its dimensions and their corresponding needs (Monod, Rochat, Büla, \& 
Spencer, 2010). Another strength of this study is the reliance on the GDS-15, an instrument widely used in various clinical settings, to assess depressive symptoms, which resulted in adequate ecological validity. Moreover, factorial analysis offered a useful way to explore the relationship between spiritual distress and depressive symptoms (Tsuang \& Simpson, 2008).

This study has some limitations. First, the results apply only to elderly geriatric inpatients without severe cognitive impairment, and generalization of these results to patients with cognitive impairment or psychiatric comorbidities may not be possible. Second, the GDS-15 and the SDAT were conducted at different times, and in the same order (GDS-15 followed by SDAT); therefore, symptomatic change may have occurred in some patients between the two interviews. However, this bias is likely to be small, as all examinations were performed within a short 72-hour timeframe.

\section{Conclusion and future research}

Depressive symptoms and spiritual distress were moderately related but clearly distinct dimensions.

Future research could further explore this question by using more specific instruments to assess depression, such as the PHQ-9 instrument (Kroenke, Spitzer, \& Williams, 2001) which has demonstrated good performances (sensitivity $82 \%$, specificity $87 \%$ ) to diagnose depression in elderly patients (Richardson, He, Podgorski, Tu, \& Conwell, 2010). Moreover, a categorical approach instead of a dimensional approach of depression may also be explored and could yield different results. 


\section{References}

Balboni, M. J., Puchalski, C. M., \& Peteet, J. R. (2014). The relationship between medicine, spirituality and religion: three models for integration. Journal of Religion and Health, 53, 1586-1598. doi:10.1007/s10943-014-9901-8

Beekman, A. T., Copeland, J. R., \& Prince, M. J. (1999). Review of community prevalence of depression in later life. The British Journal of Psychiatry, 174, 307-311. doi:10.1192/bjp.174.4.307

Bekelman, D. B., Dy, S. M., Becker, D. M., Wittstein, I. S., Hendricks, D. E., Yamashita, T. E., \& Gottlieb, S. H. (2007). Spiritual well-being and depression in patients with heart failure. Journal of General Internal Medicine, 22, 470-477. doi:10.1007/s11606-0060044-9

Blank, K., Gruman, C., \& Robison, J. T. (2004). Case-finding for depression in elderly people: balancing ease of administration with validity in varied treatment settings. The Journals of Gerontology. Series A, Biological Sciences and Medical Sciences, 59, 378-384. doi:10.1093/gerona/59.4.M378

Blazer, D. G. (2003). Depression in late life: review and commentary. The Journals of Gerontology. Series A, Biological Sciences and Medical Sciences, 58, 249-265. doi:10.1093/gerona/58.3.M249

Brown, A. E., Whitney, S. N., \& Duffy, J. D. (2006). The physician's role in the assessment and treatment of spiritual distress at the end of life. Palliative \& Supportive Care, 4 , 81-86. doi:10.1017/S1478951506060093

Cialdella, P., Guillaud-Bataille, J. M., Gausset, M. F., Terra, J. L., Gerin, P., Palliard, E., \& Jouishomme, J. C. (1992). Etude sur l'unidimensionnalité de l'échelle de dépression gériatrique de Yesavage et Brink : Comparaison entre méthodes classiques et modèle 
de Rasch [Study of the uni-dimensionality of the Yesavage-Brinck geriatric depression scale. Comparison between classical methods and Rasch's model]. Encephale, 18, $537-544$.

Daaleman, T. P., \& Frey, B. B. (2004). The Spirituality Index of Well-Being: A new instrument for health-related quality-of-life research. The Annals of Family Medicine, 2, 499-503. doi:10.1370/afm.89

Daaleman, T. P., Frey, B. B., Wallace, D., \& Studenski, S. A. (2002). Spirituality Index of Well-Being Scale: development and testing of a new measure. The Journal of Family Practice, 51, 952.

Dennis, M., Kadri, A., \& Coffey, J. (2012). Depression in older people in the general hospital: a systematic review of screening instruments. Age and Ageing, 41, 148-154. doi:10.1093/ageing/afr169

Folstein, M. F., Folstein, S. E., \& McHugh, P. R. (1975). «Mini-mental state ». A pratical method for grading the cognitive state of patients for the clinician. Journal of Psychiatric Research, 12, 189-198. doi:10.1016/0022-3956(75)90026-6

Helvik, A. S., Skancke, R. H., \& Selbaek, G. (2010). Screening for depression in elderly medical inpatients from rural area of Norway: prevalence and associated factors. International Journal of Geriatric Psychiatry, 25, 150-159. doi:10.1002/gps.2312

Huguelet, P., \& Koenig, H. G. (2009). Religion and spirituality in psychiatry. Cambridge: Cambridge University Press.

Hungelmann, J., Kenkel-Rossi, E., Klassen, L., \& Stollenwerk, R. (1989). Development of the JAREL spiritual well-being scale. In Carroll-Johnson, R. M. (Ed.), Classification of Nursing Diagnosis: proceedings of the eight conference, North American Diagnosis Association (pp. 393-398). 
Katz, S., Downs, T. D., Cash, H. R., \& Grotz, R. C. (1970). Progress in development of the index of ADL. Gerontologist, 10, 20-30. doi:10.1093/geront/10.1_Part_1.20

Kim, G., DeCoster, J., Huang, C. H., \& Bryant, A. N. (2013). A meta-analysis of the factor structure of the Geriatric Depression Scale (GDS): the effects of language. International Psychogeriatrics, 25, 71-81. doi:10.1017/S1041610212001421

Kroenke, K., Spitzer, R. L., \& Williams, J. B. (2001). The PHQ-9. Validity of a brief depression severity measure. Journal of General Internal Medicine, 16, 606-613. doi:10.1046/j.1525-1497.2001.016009606.x

McClain, C. S., Rosenfeld, B., \& Breitbart, W. (2003). Effect of spiritual well-being on endof-life despair in terminally-ill cancer patients. Lancet, 361, 1603-1607. doi:10.1016/S0140-6736(03)13310-7

Monod, S., Martin, E., Spencer, B., Rochat, E., \& Büla, C. (2012). Validation of the spiritual distress assessment tool in older hospitalized patients. BMC Geriatrics, 12, 13. doi:10.1186/1471-2318-12-13

Monod, S., Rochat, E., Büla, C., Jobin, G., Martin, E., \& Spencer, B. (2010). The spiritual distress assessment tool: an instrument to assess spiritual distress in hospitalised elderly persons. BMC Geriatrics, 10, 88. doi:10.1186/1471-2318-10-88

Monod, S., Rochat, E., Büla, C., \& Spencer, B. (2010). The Spiritual Needs Model: spirituality assessment in the geriatric hospital setting. Journal of Religion, Spirituality \& Aging, 22, 271-282. doi:10.1080/15528030.2010.509987

Moreira-Almeida, A., \& Koenig, H. G. (2006). Retaining the meaning of the words religiousness and spirituality: a commentary on the WHOQOL SRPB group's «A cross-cultural study of spirituality, religion, and personal beliefs as components of quality of life » (62: 6, 2005, 1486-1497). Social Science \& Medicine, 63, 843-845. 
doi:10.1016/j.socscimed.2006.03.001

Mulsant, B. H., \& Ganguli, M. (1999). Epidemiology and diagnosis of depression in late life. The Journal of Clinical Psychiatry, 60(S20), 9-15.

Nakajima, G. A., \& Wenger, N. S. (2007). Quality indicators for the care of depression in vulnerable elders. Journal of the American Geriatrics Society, 55, S302-S311. doi:10.1111/j.1532-5415.2007.01336.x

Nelson, C. J., Rosenfeld, B., Breitbart, W., \& Galietta, M. (2002). Spirituality, religion, and depression in the terminally ill. Psychosomatics, 43, 213-220. doi:10.1176/appi.psy.43.3.213

Puchalski, C. M., Vitillo, R., Hull, S. K., \& Reller, N. (2014). Improving the spiritual dimension of whole person care: reaching national and international consensus. Journal of Palliative Medicine, 17, 642-656. doi:10.1089/jpm.2014.9427

Richardson, T. M., He, H., Podgorski, C., Tu, X., \& Conwell, Y. (2010). Screening depression aging services clients. The American Journal of Geriatric Psychiatry, 18, 1116-1123. doi: 10.1097/JGP.0b013e3181dd1c26

Rosmarin, D. H., Malloy, M. C., \& Forester, B. P. (2014). Spiritual struggle and affective symptoms among geriatric mood disordered patients. International Journal of Geriatric Psychiatry, 29, 653-660. doi:10.1002/gps.4052

Sheikh, J. I., \& Yesavage, J. A. (1986). Geriatric Depression Scale (GDS): recent evidence and development of a shorter version. Clinical Gerontologist, 5, 165-173. doi:10.1300/J018v05n01_09

Sheikh, J. I., Yesavage, J. A., Brooks, J. O., Friedman, L., Gratzinger, P., Hill, R. D., Zadeik, A., Crook, T. (1991). Proposed factor structure of the geriatric depression scale. International Psychogeriatrics, 3, 23-28. doi:10.1017/S1041610291000480 
Sulmasy, D. P. (2002). A biopsychosocial-spiritual model for the care of patients at the end of life. Gerontologist, 42(S3), 24-33. doi:10.1093/geront/42.suppl_3.24

Tsuang, M. T., \& Simpson, J. C. (2008). Commentary on Koenig (2008): « Concerns about measuring "spirituality" in research ». The Journal of Nervous and Mental Disease, 196, 647-649. doi:10.1097/NMD.0b013e3181813570

Villagomeza, L. R. (2005). Spiritual distress in adult cancer patients: toward conceptual clarity. Holistic Nursing Practice, 19, 285-294.

Visser, A., Garssen, B., \& Vingerhoets, A. (2010). Spirituality and well-being in cancer patients: a review. Psycho-Oncology, 19, 565-572. doi:10.1002/pon.1626

Wancata, J., Alexandrowicz, R., Marquart, B., Weiss, M., \& Friedrich, F. (2006). The criterion validity of the Geriatric Depression Scale: a systematic review. Acta Psychiatrica Scandinavica, 114, 398-410. doi:10.1111/j.1600-0447.2006.00888.x

Watson, L. C., \& Pignone, M. P. (2003). Screening accuracy for late-life depression in primary care: a systematic review. The Journal of Family Practice, 52, 956-964.

Yesavage, J. A., Brink, T. L., Rose, T. L., Lum, O., Huang, V., Adey, M., \& Leirer, V. O. (1983). Development and validation of a geriatric depression screening scale: a preliminary report. Journal of Psychiatric Research, 17, 37-49. doi:10.1016/00223956(82)90033-4 